\title{
SEISMIC DESIGN OF MASONRY STRUCTURES TO THE NEW PROVISIONAL NEW ZEALAND STANDARD NZS 4230P
}

\author{
M J N Priestley*
}

\begin{abstract}
SUMMARY
Background to seismic design aspects of the provisional New Zealand Code of Practice for Masonry structural Design is given. Emphasis is given to reasons for differences in the provisional code from an earlier draft code. The changes include improved compatibility with the current Loadings Code NZS 4203 and the Concrete Design Code NZS 3101, provisions of simplified rules to ensure adequate ductility capacity, and additional information to provide guidance for ductile design of masonry frames. Some experimental results are presented to provide support for the provisions.
\end{abstract}

\section{INTRODUCTION}

In 1980 a draft Masonry Design Code ${ }^{2}$ was issued by the Standards Association of New Zealand (SANZ) for comment. Seismic design aspects dominated the code provisions, and background to these was given in a paper published in the December 1980 issue of the Bulletin. The code-drafting committee reconvened in early 1982 to consider the comments that had been received. There was little controversy about technical detail, particularly relating to seismic design aspects, but fairly widespread dissatisfaction with the format was apparent. A common comment was that greater compatibility with the New Zealand Concrete Design Code should be attempted, both in format and sequence of provisions, and also, where possible, in specific design equations. This made sense, as the draft Masonry Code specified the Concrete code as a back-up document, to be applied where specific provisions were not included in the Masonry Code.

A further area of some controversy, not unexpected by the code committee, related to conflict between provisions of the Masonry Code and the Loadings code relating to structural type factors ${ }^{5}$ for seismic loading. The ' $S$ ' factor modifies the level of seismic loading by direct proportion, and may be thought of as an inverse measure of the ductility capacity of the appropriate structural form. In the draft Masonry Code the committee had taken the viewpoint that structural type factors could not be divorced from the structural material. Thus, for example, a coupled shear wall might represent an excellent structural solution for providing seismic resistance in a concrete

Reader in Civil Engineering, University of Canterbury structure, but might be considerably less satisfactory when constructed in masonry, because of the ductility demand on spandrel beams which could not be adequately detailed in masonry.

Although this argument was not contested, SANZ took the view, through its design liaison committee, that loadings (which include the ' $S$ ' factor) could not be specified in a Materials Design Code. Hence, since the Loadings code currently specifies a low $S$ factor for coupled shear walls and ductile frames, regardless of material type, it was necessary for the Masonry Design Code to allow such designs, and to include the necessary provisions to ensure satisfactory seismic response from them.

On the basis of these comments, an extensive reorganisation of the draft code was undertaken. The format was changed to glosely parallel the Concrete Design code ${ }^{4}$, so that chapter headings, and generally subsections in the two codes correspond. For example, section 7.3.6 in both codes is entitled 'Design of Shear Reinforcement'. Adopting the concrete code format also means that each chapter is divided into an introductory section of general principles and requirements applicable to all members, a section of additional principles and requirements for members not designed for seismic loading, and a section on additional principles and requirements for members designed for seismic loading. It is thus expected that designers familiar with the concrete code will find 'driving' the Masonry Code comparatively straightforward. This should. be aided by a reduction in number, and simplification in content, of clauses applicable to a given situation.

The cloning to the Concrete code has not, however, been slavish. The real 
differences in material behaviour are reflected in the code provisions, irrelevant material (such as Chapter 11, in the Concrete Code: Floor Slabs) has been omitted, and new material (such as Chapter 11 in the Masonry Code: Non-Structural walls) has been included.

This paper provides some additional background material on the more important changes of the provisional code from its predecessor, insofar as they relate to seismic design.

\section{DESIGN STRESSES}

(6, Pesign to most overseas Masonry Codes , and to the 8 previous New Zealand Masonry Design Code ${ }^{8}$ is based on elastic design to specified stress levels. The dangers associated with an elastic design philosophy were identified in reference 3, which noted that the draft Masonry Design Code ${ }^{2}$ specified ultimate strength design as the preferred design approach for seismic loading, but allowed elastic design to higher lateral force levels, corresponding to the 'alternative design procedure' specified in the New Zealand Loadings code ${ }^{5}$. In reviewing comments on the draft code, it became apparent that there were no advantages to elastic design from a computational or structural safety viewpoint, and considerable disadvantages in terms of structural efficiency, and general conceptual understanding of masonry performance. Further, strong doubts were expressed about the validity of a design approach whose results would be strongly influenced by consideration of creep, shrinkage (or swelling), thermal strains, or settlements, but which commonly ignored these effects in analyses. As is well known, ultimate strength is rather insensitive to these actions. As a consequence, the elastic design option has been dropped from the 1985 provisional Masonry Design Code, which thus becomes a true ultimate strength design code.

Minor changes to allowable ultimate stress levels resulted from the review process. Table 1 lists the revised stress limits specified in the provisional code. Distinction is made between the levels of nominal shear stress permitted in plastic hinge regions, and in all other regions. Linear interpolation between the two levels is permitted when the ideal shear strength corresponds to lateral loading commensurate with SM factors between 3 and 4 , indicating near-elastic response, where $S$ and $M$ are the structural type and material factors respectively.

This approach recognises the improved shear performance of -regions where plastic hinging will not occur, and replaces a more restrictive requirement in the draft code. In this context it should be noted that ${ }_{5}$ the 1984 version of the Loadings code specifies a reduction in the $M$ factor for masonry from 1.2 to 1.0 .

As with the draft code, design masonry compression strengths greater than $\mathrm{f}_{\mathrm{m}}^{\prime}=8 \mathrm{MPa}$ are permitted only for Grade
A masonry, and only provided the higher value is supported by tests. The default option of $8 \mathrm{MPa}$ does not require test samples to be taken. However, it has been recognised that the earlier requirement of prism testing to support the higher stress levels was onerous, as the size and mass of the prisms were large, and very few testing establishments had suitable machines for testing the prisms. Also, theoretical research carried pyt since the draft code was written 9 , indicated that prism strength of concrete masonry could be related to strength of the constituent properties by the expression

$$
f_{m}^{\prime}=\phi\left(0.59 \alpha f_{c b}^{\prime}+0.90(1-\alpha) f_{g}^{\prime}\right)
$$

where $f^{\prime}$ and $f^{\prime}$ are the compression strength of the concrete masonry unit, and the grout respectively, $\alpha$ is the maximum ratio of net area to gross area of the masonry unit, and $\phi$ is a strength reduction factor reflecting expected scatter of test results. Note that the mortar compression strength does not appear in equation 1 , as theoretical considerations indicated that its significance on prism compression strength was minor.

A comparison between a wide range of experimental results from New zealand and overseas, with predicted strength from equation 1 is included in figure 1 . It will be seen that the theoretical curve for $\phi=1$ provides a good average prediction of strength, and that $\phi=0,75$ represents an effective lower bound . On the basis of this work, the provisional masonry code accepts compression strength testing of grout and masonry unit as a basis for enhanced compression design strength for concrete masonry using equation 1 with $\phi=0.75$, which has been rounded to give

$$
f_{m}^{\prime}=0.45 \alpha f_{c b}^{\prime}+0.675(1-\alpha) f_{g}^{\prime}
$$

No such equation has yet been established for clay brick grouted masonry, but it is hoped that testing in the near future will result in an equivalent simple expression.

\section{DUCTILITY}

Considerable emphasis was given on ductility requirements for masonry walls in the earlier paper ${ }^{3}$ discussing the draft masonry code, though the code itself did not require specific consideration of ductility capacity, nor include specific detailing requirements (such as lateral confinement) to ensure adequate ductility. The draft code noted, however, that the ductility capacity of reinforced masonry walls would be limited by the low ultimate compression strain of 0.0025 for unconfined masonry. This value, which was tentative at the time of preparing the draft cpple $e^{3}$ has been confirmed by further testing, which has also resulted in an ultimate compression strain of 0.008 being recommended for concrete masonry confined by mortar bed confining plates of $3 \mathrm{~mm}$ thickness, constructed of either stainless 
or galvanised steel (see figure 2).

Rather than performing the somewhat cumbersome calculations presented in reference 3, design charts such as that of figure 3 have been prepared $(12,13)$ relating the ductility capacity, $\mu_{3}$ of masonry walls of aspect ratio (height/length) $=3$, to the axial load ratio $\mathrm{N}_{u} / \mathrm{f}^{\prime} \mathrm{A}^{\prime}$, the longitudinal steel ratio $p=A_{\text {st }} / t \cdot l_{w},(t=$ thickness, $\ell_{W}=$ wall length) and yield strength $\mathrm{f}_{\mathrm{Y}}$, and the masonry compression strength $f_{m}$. These may be modified to predict the ductility capacity of a wall of aspect ratio $A$ by the relationship

$$
\frac{3.43\left(\mu_{3}-1\right)(1-0.375 / \mathrm{A})}{\mathrm{A}}
$$

Equation 3 can be simply derived from equations given in reference 12 .

Charts similar to figure 3 have been prepared for walls reinforced with steel of different yield strength, or confined by mortar bed confining plates.

As an alternative to the detailed assessment of ductility capacity afforded by the ductility charts, the provisional code sets simple guidelines limiting the depth of the compression zone at ultimate strength. Since the ultimate curvature $\phi_{u}$ of a masonry plastic hinge may be written

$$
\phi_{\mathrm{u}}=\varepsilon_{\mathrm{cu}} / \mathrm{c}
$$

where $\varepsilon_{\mathrm{cu}}$ is the ultimate compression strain $(0.0025$ for unconfined masonry) and $c$ is the distance from the extreme compression fibre to the neutral axis, it is clear that ultimate curvature, and hence ductility capacity, are inversely related to $c$. The analysis that led to the ductility charts of figure 3 and references 12 and 13 , also provided information on the relationship between the depth of the compression zone, and the ductility capacity. It was found that for walls of aspect ratio $h_{\mathrm{w}} / \ell_{\mathrm{w}} \leq 3$, the ductility capacity could be expressed as

$$
\mu \geq 0.4 l_{\mathrm{W}} / \mathrm{C}
$$

where $l_{w}$ is the wall length.

The 1984 version of the Loadings Code implies a relationship between required ductility and specified structural type factor of

$$
\mu=4 / \mathrm{S}
$$

This relationship results from the implications of elastic response corresponding to $S M=4$, as specified in reference 5, the masonry materials factor being taken as $M=1$ and the equal displacement approximation of seismic response of ductile systems ${ }^{3}$. Combining equations 5 and 6 thus requires that

$$
\mathrm{c} \leq 0.1 \mathrm{~s} \ell_{\mathrm{W}}
$$

Equation 7 is included in the provisional code, and may be used to check ductility capacity for walls of aspect ratio less than 3. For taller walls, or where the designer wants a more precise estimate of ductility capacity, ductility charts such as figure 3 must be used to ensure the ductility capacity exceeds the level implied by equation 6 . It should be noted that equation 7 is generally conservative, particularly for squat walls, and a wall violating the requirements of equation 7 may still be found to have adequate ductility using the more detailed approach afforded by the ductility charts.

Equation 7 is similar to equation 10-3 of the New zealand Concrete Design Code which requires the compression depth of ductile walls to be less than

$$
c=0.1 \phi_{0} S l_{W}
$$

unless confinement of the compression zone is provided, where $\phi$ is the ratio of the wall base moment of resistance to the wall base moment resulting from code specified loading. Equation 8 appears to imply that $\phi_{O}$ is a quantity that may be depended upon in the normal design situation. $\phi_{0}$ includes overstrength due to material strengths (particularly steel yield strength) exceeding the specified nominal value, effects of flexural strength reduction factors, overstrength resulting from strain hardening of reinforcement, and overstrength due to provision of extra reinforcement above the amount required to satisfy the design base moment. The Masonry Design Code committee took the viewpoint that only the latter could be considered dependable, and hence the $\phi_{0}$ factor is not included in equation 7. However, the commentary to the masonry code notes that where dependable flexural strength is provided in excess of that required for the design $S$ factor, the maximum neutral axis depth in equation 7 may be increased in proportion to the excess strength provided.

\section{SEISMIC REQUIREMENTS FOR STRUCTURES OF} LIMITED DUCTILITY

To a considerable extent, the seismic provisions throughout the provisional Masonry Design Code may be thought of as relating to structures of limited ductility, since they are based on limiting the ultimate compression strain to $\varepsilon_{\mathrm{Cu}}=0.0025$. This differs significantIy from the New Zealand Concrete Design Code where ultimate strains exceeding the nominal crushing strain of 0.003 are expected in beam, column and wall plastic hinges and where detailing requirements are specified to ensure adequate confinement of core concrete, and support of compression bars against buckling, after spalling of cover concrete has occurred. Nevertheless the masonry code provisions, as noted in the previous section, are intended to assure fully ductile behaviour commensurate with structural type factors as low as $S=0.8$.

Since the revised version of the Loadings code $^{5}$ identified a class of limited ductility structures to be designed for $S=2.0$, and since chapter 14 of the New Zealand Concrete Design Code 4 provides rather detailed requirements for such 
structures, the provisional masonry code was obliged to present an appropriate chapter. In drafting it, the committee took the view that the chapter should provide a simple alternative to capacity design where the penalty of designing to higher force levels was not great.

The emphasis was on simplicity. The entire provisions occupy less than two pages, and unlike the concrete code, do not introduce a set of new variables and concepts to be understood by the designer. Protection against accidental plastic hinging or shear failure is provided by designing for forces corresponding to the following $S$ factors:

Flexure within plastic hinges : $\quad S=2.0$ Flexure outside plastic hinges: $\quad S=3.0$ Shear, all locations : $S=4.0$

Within potential hinge regions, masonry shear resisting mechanisms may contribute up to half the values listed for 'general conditions' in table 1 . Compression depths in plastic hinge regions are required to satisfy

$$
C \leq 0.2 l_{W}
$$

It will be seen that equation 8 is obtained by substituting $S=2$ into equation 7 .

It is expected that this chapter will be used for design of many minor masonry buildings.

\section{MASONRY FRAMES}

The ${ }_{5}$ SANZ ruling on gompatibility with loadings and concrete codes required the masonry code committee to consider ductile design of masonry frames. The loadings code specifies an $S$ factor of 0.8 for ductile frames, implying $\mu=5$ (see equation 6), while the design philosophy for concrete frames stipulates capacity design based on the weak beam/strong column concept. In the draft masonry code, ductile design of masonry frames had been restricted to one or two storey frames with column sway mechanisms, for which $S=2.4$ was specified. These limitations reflected uncertainty about the ductility capacity of masonry beams, and the strength and behaviour of masonry beam/ column joints, both of which were untested quantities.

Figure 4 shows a sketch of a masonry frame whose proportions might be considered to provide the potential for conventional ductile frame action. The frame is considered to be constructed from hollow concrete masonry units, with the column and beam elements having the same thickness (which corresponds to that of the masonry unit). As shown in figure 4, and as explained shortly, the column units are comparatively wide, and it might be appropriate to refer to the structure as a 'wall-frame'. An alternative form of concrete masonry construction using column sections constructed using two masonry pilaster channel units of $190 \mathrm{x}$ $390 \mathrm{~mm}$ outside dimensions to provide a
$390 \times 390 \mathrm{~mm}$ square column with a substantial grouted core is possible. However, the low seismic resistance of such columns would make this form of construction unsuitable where significant lateral seismic forces are to be transmitted.

Beam flexural reinforcement would be uniformly distributed with depth, with open-end bond-beam units used throughout the beam to improve beam structural integrity, and to facilitate steel placement. As has been noted earlier when commenting about flexural resistance of walls, there is no significant strength penalty in uniformly distributing the flexural reinforcement through the beam depth compared with concentrating the same amount of reinforcement in two layers adjacent to top and bottom faces of the beam. However the latter, and conventional, configuration is unsuitable for masonry construction because the limited grout width will result in congestion, and grouting difficulties. Uniformly distributed reinforcement is better restrained against compression buckling, provides better resistance to sliding shear by dowell action, and results in a somewhat greater depth of the flexural compression zone, enhancing compression shear transfer.

Design levels of beam shear force and column flexure and shear would be calculated using capacity design principles, corresponding to development of maximum feasible flexural strength in the designated beam plastic hinges. Within the beam plastic hinges, all shear would be carried by transverse reinforcement.

Figure 5 shows the typical layout of reinforcement in a masonry beam section comprising four layers of $190 \mathrm{~mm}$ wide concrete masonry open-end bond-beam units. Note that the bottom course of blocks is laid inverted in order to facilitate clean out of mortar droppings, and enable the bottom beam bar to be placed with maximum eccentricity.

\section{Ductility Capacity of Masonry Frames}

Although general expressions such as equation 3 may be written for the ductility capacity of masonry shear walls, no unique equivalent expression is possible for masonry frames, as the relative contribution to elastic deformation from beams, columns and joint deformation depend on the overall frame geometry as well as beam and column section properties while the inelastic deformation is dependent only on the plastic rotation of the beam hinges.

Figure 6 illustrates the procedure for calculating the ductility capacity of a typical masonry unit (figure 6a) consisting of columns and beams between contraflexure points assumed to occur at midlength of the column or beam respectively. Provided that the beams at different floors are proportioned to yield at the same level of earthquake excitation then the ductility of this unit approximates to that of the complete frame.

As shown in figure $6 \mathrm{~b}$ the lateral 
yield displacement of the upper column contraflexure point relative to the lower contraflexure point can be expressed as

$$
\Delta_{y}=\left(\theta_{C e}+\theta_{j e}\right) l_{C}+\Delta_{C T}+\Delta_{C B}
$$

where $\Delta_{C T}$ and $\Delta_{C B}$ are the structural deflection of the top and bottom column elements under the lateral loading, $\theta_{j e}$ is the elastic shear rotation of the joint, and $\theta$ is the column rotation at the centre of the joint resulting from beam structural deformation. Clearly $\theta$ ce is related to the beam elastic rotation $\theta_{\text {be }}$ by the expression

$$
\left.\theta_{c e}=\theta_{b e} \frac{l_{n}}{\left(l_{n}+h_{c}\right.}\right)
$$

In equations 9 and $10, \ell_{n}, \ell_{C}$ and $h_{C}$ are defined by figure 6a. Equation 9 may be expressed as

$$
\Delta_{Y}=K \cdot \theta_{C e^{l}}
$$

where $\mathrm{K}$ is the ratio of yield displacement to displacement resulting from beam rotation alone.

The capacity design approach ensures all plastic rotations occur in the hinges. From figure 6c,

$$
\Delta_{p}=\theta_{C p}{ }^{l} c
$$

where

$$
\theta_{c p}=\theta_{p}\left(\frac{l_{n}}{l_{n}+h_{c}}\right)
$$

is the column rotation resulting from beam plastic rotation $\theta_{\mathrm{p}}$.

The ductility capacity of the frame unit is thus

$$
\begin{aligned}
\mu_{f} & =\frac{\Delta_{y}+\Delta_{p}}{\Delta_{y}} \\
& =1+\frac{\theta_{c p}}{K \theta_{c e}} \\
& =1+\frac{\theta_{p}}{K \theta_{b e}} \\
& =1+\frac{\left(\mu_{b}-1\right)}{K}
\end{aligned}
$$

where $\mu_{\mathrm{b}}$ is the displacement ductility capacity of the beam. Equation 13 indicates that if $\mathrm{K}=1$, implying a rigid joint and column, the ductility capacity of the frame $\mu_{f}$ is equal to that of the beam, but that additional flexibility in the joint and column will reduce the frame ductility capacity. The provisional design code ${ }^{1}$ has assumed that as a consequence of additional flexibility,

$$
\mu_{f}=0.75 \mu_{b}
$$

An expression limiting the compression depth in beam plastic hinges can now be written, by considering the half-beams on either side of the joint as equivalent cantilever shear walls. Equation 7 applies for a shear wall of wall-height/ base-length $=3$. This implies an effective aspect ratio of 2 if based on the height of the centre of lateral seismic force, since this is at roughly two-thirds of the building height for the code distribution of lateral loads. Hence equations 7 and 14 imply a required compression depth of

$$
c \leq 0.075 \mathrm{Sh}_{\mathrm{b}}
$$

for a beam whose effective aspect ratio is

$$
A=\left(\frac{l_{n}}{2 h_{b}}\right)=2
$$

Since ductility capacity is approximately inversely proportional to aspect ratio, equations 15 and 16 can be combined to give

$$
\left.c \leq 0.075 \mathrm{~S} \mathrm{~h} \mathrm{~b}_{\mathrm{b}} \frac{2}{\left(\mathrm{l}_{\mathrm{n}} / 2 \mathrm{~h}_{\mathrm{b}}\right.}\right)
$$

that is

$$
c \leq \frac{0.3 \mathrm{~s} \mathrm{~h}_{\mathrm{b}}{ }^{2}}{l_{\mathrm{n}}}
$$

This limitation is included in the provisional code. For one or two storey frames, the loadings code ${ }^{5}$ permits a column sidesway mechanism. In such cases, similar arguments to those presented above result in a limitation on the depth of the compression zone in the column plastic hinge of

$$
c \leq \frac{0.2 \mathrm{~s} \mathrm{~h}_{\mathrm{c}}{ }^{2}}{l_{\mathrm{n}}}
$$

The reduction in compression depth in equation 18 relative to equation 17 reflects the lower ratio of frame ductility capacity to column ductility capacity inherent in the soft-storey mechanism of a two-storey building with a column sway mechanism.

\section{Joint Design for Masonry Frames}

The design of the joint region between beams and columns requires special consideration. Two aspects are of particular importance:

1. the width of the joint (parallel to the beam axis) must be sufficient to allow the necessary change in beam reinforcement stress through the joint to be developed by bond, and

2. the dimensions and reinforcement of the joint must be adequate to carry the shear forces developed in the joint by the moment gradient across the joint.

The beam moment reversal across the joint implies that beam reinforcement may be yielding in tension at one side of the joint, and yielding in compression at the other side. Consequently the joint width must be at least equal to the sum of the 
tension and compression development lengths for the reinforcement. Thus for a given column width, the diameter of the beam flexural reinforcement is limited, The provisional masonry design code requires that

$$
a_{b} \leq h_{C} / 90 \text { for } f_{y}=275 \mathrm{MPa}
$$

and

$$
a_{b} \leq h_{C} / 120 \text { for } f_{y}=380 \mathrm{MPa}
$$

where $d_{b}$ is the diameter of the beam flexural reinforcement.

Similar considerations limit the diameter of column flexural reinforcement, due to the moment gradient vertically through the joint. However, since the capacity design approach will reduce column reinforcement stresses, less stringent requirements are appropriate. Reference 1 requires

$$
a_{c} \leq h_{b} / 50 \text { for } f_{y}=275 \mathrm{MPa}
$$

and

$$
a_{C} \leq h_{b} / 70 \text { for } f_{y}=380 \mathrm{MPa}
$$

The limitations of equations 19 and 20 are very much more stringent than currently adopted for reinforced concrete frames (the New Zealand Concrete Design Code ${ }^{4}$ requires $a_{b} \leq h_{c} / 25$ for $f_{y}=275 \mathrm{MPa}$, and American practice is even less stringent). However, it appears that the only way the very high bond stresses which correspond to such small $h_{\mathrm{c}} / \mathrm{d}_{\mathrm{b}}$ ratios can develop is a result of lateral confinement of the joint core region by closed joint stirrups. Since reinforcement in a masonry beam/column joint will all be in the same plane, lateral confining pressures cannot develop, and without specific experimental evidence to support a reduction in development lengths for the joint, it appears prudent to make these similar to other parts of the structure.

Because of the lack of relevant experimental information for masonry joints, the provisional masonry code requires shear reinforcement for the joint to be based on a conservative interpretation of the principles for reinforced concrete incorporated in the Concrete Design code. Horizontal joint shear force is found in the usual manner from equilibrium considerations under the full set of horizontal forces (reinforcement and masonry forces at the beam interfaces, and column shears at the column interfaces) acting on the joint. Where beam hinges from immediately adjacent to the joint, all of the horizontal joint shear must be carried on joint shear reinforcement. As with reinforced concrete, vertical joint shear design is subject to less stringent requirements, and generally no additional joint reinforcement will be necessary.

\section{Testing of a Masonry Beam/Column Unit}

Because of the lack of experience with masonry ductile frames, a full size concrete masonry joint unit representing the region between beam and column contraflexure points circled in figure 4 was constructed and tested at the University of Canterbury under inelastic cyclic loading, simulating earthquake excitation. Test unit dimensions, based on a bay length of 5 metres and a storey height of 3 metres, and reinforcement details are shown in figure 4. Note that with the $20 \mathrm{~mm}$ Grade 275 beam reinforcement, the column width of 1.8 metres is the minimum required to satisfy equation $19 \mathrm{a}$. Open-end bond-beam units $190 \mathrm{~mm}$ wide were used throughout the beam, joint and column, except that full or half lintel units were used as end closers.

Beam flexural reinforcement provided hogging and sagging ideal moment capacities of $127.9 \mathrm{kNm}$ and $115.8 \mathrm{kNm}$ respectively. The lack of equality resulted from a slightly eccentric layout of beam reinforcement dictated by the heights of the depressed webs of the beam units. Beam shear reinforcement, and joint and column reinforcement were based on the assumed development of beam overstrength moments equal to 1.25 times ideal strength. Note that the joint reinforcement consists of $\mathrm{D} 20$ bars in the same horizontal flues as the beam flexural steel.

A schematic of the test set up is shown in figure 8 . The bottom hinge of the column was connected to a strong floor, with lateral load being applied to the top hinge through a load cell and doubleacting hydraulic jack reacting against a steel reaction frame. The ends of the beams were supported by pin-ended struts, which provided vertical reactions, but allowed unrestrained horizontal displacement. No vertical load was applied to the column, since axial load levels in masonry frames are typically low, and it was felt that vertical compression would improve joint performance. Lateral stability was provided by transverse rollers at the positions marked in figure 8 . These rollers allowed free inplane movement.

Load was applied in a series of displacement-controlled cycles to gradually increasing displacement ductility levels. An initial elastic cycle was imposed, with maximum loads of $69 \%$ of the theoretical ultimate capacity, thus corresponding to first yield of the extreme tension rebar of the beam. The so-called 'yield' displacement, $\Delta_{y}$, was found graphically by extropolating a straight line from zero through the average load-displacement point at first yield, measured at the level of load application, to the lateral load corresponding to theoretical ultimate flexural capacity of the beam hinges. The subsequent load history consisted of three cycles to a displacement ductility factor of $\mu=1$ (that is, $\Delta=\Delta_{y}$ ) followed by three complete cycles to $\mu=2,3,4$ and 6 respectively. The final cycle consisted of pushing the test unit to $\mu=6$, then puling it to $\mu=10$.

Results from the test programme indicated dependable ductile behaviour as shown by the load-deflection hysteresis loops of figure 9. Included in this 
figure is the theoretical ultimate lateral load of $\mathrm{P}_{\mathrm{u}}=121 \mathrm{kN}$, which was based on the development of beam plastic hinging at the ideal beam moment capacities using the measured materials properties of table 2, and an ultimate compression strain of $\varepsilon_{\text {u }}=0.0025$. Also included in figure 9 are the theoretical load $P_{y}$ at which the extreme tension bar in the beams first reached yield stress, and the design 'dependable' strength of $0.85 \mathrm{P}_{\mathrm{u}}$.

Very satisfactory performance is indicated by figure 9. Initial peak loads at $\mu=2,3$ and 4 are within $\pm 5 \%$ of $P_{\mu}$, and load degradation during subsequent cycles at a given ductility level is comparatively minor. The loop shape is very stable, and indicates good energy dissipation capacity. Crushing of mortar and splitting of face shells in the beam hinge compression zones was first noted at $\mu=4$, but did not result in significant load degradation. At $\mu=6$, spalling of face shells and buckling of the compression reinforcement occurred, resulting in the degradation of response apparent in figure 9. Figure 10 shows the condition of the unit after sustaining displacement to $\mu=10$. Note the extent of spalling of the face shells and failure of the grout core, leaving beam reinforcement exposed. The rery minor cracking of the column and joint core apparent in this figure should also be noted. Despite the extensive damage to the beam plastic hinges apparent in figure 10, the maximum load attained on loading to $\mu=10 \mathrm{still}$ exceeded the design dependable strength of $0.85 \mathrm{P}_{u}$ (see figure 9).

Figure 9 indicates that dependable ductile behaviour was obtained at $\mu=4$, but that degradation at $\mu=6$ indicated that the limits to ductility capacity had been exceeded. Equations 6 and 17 can be combined and rearranged to estimate the ductility capacity of a given frame. Thus

$$
\mu \geq \frac{1.2 h_{b}{ }^{2}}{c l_{n}}
$$

Ultimate flexural stress calculations provided a compression zone depth of 83 $\mathrm{mm}$. Thus with $\mathrm{h}_{\mathrm{b}}=790 \mathrm{~mm}$ and $l_{\mathrm{n}}=2 \mathrm{x}$ $1605=3210 \mathrm{~mm}$, equation 21 predicts

that is

$$
\mu \geq \frac{1.2 \times 790^{2}}{83 \times 3210}
$$

$$
\mu \geq 2.8
$$

This is a rather conservative estimate when compared with actual behaviour. However, it should be noted that, although strength degradation was not excessive at $\mu=4$, crushing and splitting of the masonry compression zones had already occurred.

Figure 11 shows the stress distributions along the beam reinforcement passing through the joint at peak displacement ductility levels, measured by elastic resistance strain gauges. The top and bottom bars indicate yield penetration into the joint for approximately $100 \mathrm{~mm}$, then rapid reduction of stress by bond over the next $600 \mathrm{~mm}$. Intermediate bars $(2 \mathrm{~B}$ and $3 \mathrm{~B}$ in figure 11) indicate similar behaviour, although bar $3 \mathrm{~B}$ indicates tension on both sides of the joint, while the other bars show stress reversal. The behaviour of $3 \mathrm{~B}$ is due to the comparatively small depth of the compression zones in the beam hinges at ultimate.

It is significant that the slope of the stress distribution through the joint increases with bar number, indicating higher bond stresses for the bottom bar than for the top bar. This presumably indicates a deterioration in grout properties with height above the base of the pour, which corresponded with the beam soffit, due to settlement and segregation.

The stress distributions of figure 11 indicate that development lengths were somewhat less than indicated by equation 19, even for the top bar, and in consequence it is felt that the column width. could have been reduced to $1400 \mathrm{~mm}$ without jeopardising behaviour. However it should be noted that for lower grout strengths than the $24.3 \mathrm{MPa}$ applicable to this test, such action would be unwise.

As indicated by figure 10, joint performance of the test unit was very good. The joint did not develop diagonal cracking, and the maximum stress recorded on the joint shear reinforcement, of only $83 \mathrm{MPa}$, occurred close to the beam interface and appears to have been dut: to penetration of the beam hinge into the joint, rather than from joint shear.

Figure 12 shows the computed horizontal forces acting on the joint at the maximum experimental lateral load of 126.4 $\mathrm{kN}$. Equilibrium of these forces indicates that the total joint shear force was

$$
\begin{aligned}
v_{j h} & =181.8+90.9+90.9-126.4 \\
& =237.2 \mathrm{kN}
\end{aligned}
$$

which represents a nominal joint shear stress of

$$
\begin{aligned}
v_{j h} & =\frac{v_{j h}}{h_{C} \cdot t}=\frac{237.2}{1.8 \times 0.19} \\
& =0.69 \mathrm{MPa}
\end{aligned}
$$

Experience with testing of masonry shear walls indicates that diagonal shear cracking could be expected at a lower nominal shear stress than this. However it appears that since the distribution of beam flexural reinforcement ensures that a masonry compression zone always develops at ultimate, even after cyclic loading, interaction of the beam and column masonry compression force enables a dependable diagonal compression strut to form (see figure 12) transmitting the bulk of the joint shear force. The remaining effective joint shear force is thus

$$
v_{j h}^{\prime}=2 \times 90.9-126.4=55.4 \mathrm{kN}
$$

which corresponds to a nominal joint shear stress of $0.16 \mathrm{MPa}$. It is clear that this 
was insufficient to induce diagonal cracking in the joint of the test unit. It would thus appear that the provisions of the provisional. masonry design code may be somewhat conservative for joint design. However it is felt that more testing should be carried out before relaxation of the provisions is allowed. Complete information on the test programme summarised above is available in reference 14

\section{CONCLUSIONS}

The provisional masonry design code provides detailed advice for a wider range of masonry structural forms than its draft predecessor did. This has been an inevitable result of the decision to provide a code that was fully compatible with the loadings code, and compatible with the concrete design code whenever possible. The result is a more complete document than the earlier draft code, and one that designers familiar with the concrete design code and loadings code should find easy to use.

The underlying principle of the seismic design aspects of the provisional code is that masonry will not generally have confined compression zones, and hence its ductility capacity will be limited by the rather low ultimate compression strain of $\varepsilon_{\text {u }}=0.0025$ for unconfined masonry. Provisions are included to ensure this strain is not exceeded in the different forms of ductile masonry. As an alternative, where ductility at $\varepsilon_{\mathrm{cu}}=0.0025$ is inadequate, confining plates in critical regions of the plastic hinges of shear walls may be adopted to enhance ductility capacity.

Although the above comments indicate that masonry will be based on the principle of a finite but limited ductility capacity, a separate chapter on masonry structures of limited ductility is included. This corresponds to the loadings code category for which a structural type factor of $S=2$ is appropriate. Provisions of this chapter have been kept as simple as possible, and it is envisaged that designers will adopt this approach for the design of many minor masonry structures.

Because of a lack of data on the performance of ductile masonry frames, the provisions written for such structures were assessed by comparing with results from a masonry beam/column test unit designed to the provisional code. Performance of the test unit was very satisfactory, with dependable ductile response being obtained at a structural displacement ductility of $\mu=4$. Indications from this test were that the code provisions may well be rather conservative, but further testing is required before further relaxation could be made.

\section{ACKNOWLEDGEMENTS}

The provisional masonry design code is a committee document, and full acknowledgement is made of the input of all committee members into the document in its present form. The writer believes this paper represents the consensus viewpoint of the committee, but it should be interpreted as a personal statement rather than as an official committee document.

Acknowledgement is also made of financial assistance for testing the beam/ column unit from the Ministry of Works and Development, the New Zealand Concrete Masonry Association, and the University of Canterbury. The experimental work described was part of an ME project by Chai Yuk Hon, supervised by the writer.

\section{REFERENCES}

1. "Code of Practice for Masonry Design", NZS 4230P, Standards Association of New Zealand, Wellington, 1985.

2. "Draft Masonry Design Code", DZ 4210 Part B, Standards Association of New Zealand, Wellington, 1980.

3. Priestley, $M J \mathrm{~J}$, "Seismic Design of Masonry Buildings - Background to the Draft Masonry Design Code DZ $4210^{\prime \prime}$, NZNSEE Bulletin, Vol 13, No 4, December 1980, pp 329-346.

4. "Code of Practice for the Design of Concrete Structures", NZS 3101, Standards Association of New Zealand, Wellington, 1982 .

5. "Code of Practice for General Structural Design and Design Loadings for Buildings", NZS 4203:1984, Standards Association of New Zealand, Wellington, 1984 .

6. ACI Committee 531, "Building Code Requirements for Concrete Masonry Structures (ACI 531-79) (Revised 1983) and Commentary", American Concrete Institute, Detroit, 1983.

7. "Tentative Provisions for the Development of Seismic Regulations for Buildings", Special Publication, No 510, National Bureau of Standards, Washington DC, 1978, Chapter 12 - Masonry, pp $111-166$.

8. "Design and Construction - Masonry", NZSS 1900, Ch 9.2:1964, Standards Association of New Zealand, Wellington, 32 pages.

9. Priestley, $M \mathrm{~J} \cdot \mathrm{N}$ and Chai, $\mathrm{Y} \mathrm{H}$, "Prediction of Masonry Compression Strength, Part 1", New Zealand Concrete Construction, Vol 28, March 1984, pp 11-14.

10. Priestley, $M \mathrm{~J} N$ and Chai, $\mathrm{Y} \mathrm{H}$, "Prediction of Masonry Compression Strength, Part 2", New Zealand Concrete Construction, Vol 28, April 1984, pp 21-25. 
11. Priestley, $M \quad J N$ and Elder, $D$ M, "Stress-Strain Curves for Unconfined and Confined Concrete Masonry", Journal ACI, Vol 80, No 3, May/June 1983; pp 192-201.

12. Priestley, $M \mathrm{~J} N$, "Ductility of Unconfined Masonry Shear Walls", NZNSEE Bulletin, Vol 14, No 1, March 1981, pp 12-20.

13. Priestley, $\mathrm{M} J \mathrm{~N}$, "Ductility of Confined Masonry Shear Walls", NZNSEE Bulletin, Vol 15, No 1, March 1982, pp 22-26.

14. Chai, $Y \mathrm{H}$ and Priestley, $M \mathrm{~J} N$, "Masonry Walls and Wall Frames Under Seismic Loading", Department of Civil Engineering Research Report 84-15, University of Canterbury, August 1984 132 pages.

TABLE 1 - GRADE-DEPENDENT DESIGN STRENGTHS

\begin{tabular}{|l|c|c|c|}
\hline \multirow{2}{*}{ Type of stress } & \multicolumn{2}{|c|}{ Grade of Masonry } \\
\cline { 2 - 4 } & A & B & C \\
\hline $\begin{array}{l}\text { Compression } \\
\text { Shear Provided by masonry } \\
\text { general conditions } \\
\begin{array}{l}\text { Shear provided by masonry } \\
\text { plastic hinges }\end{array}\end{array}$ & $8 *$ & 8 & 4 \\
$\begin{array}{l}\text { Maximum total shear, } \\
\text { general conditions } \\
\text { Maximum total shear, } \\
\text { plastic hinges }\end{array}$ & 0 & 0.24 & 0.12 \\
\hline
\end{tabular}

* A higher design $f_{m}^{\prime}$ may be used if substantiated by testing

TABLE 2 - MATERIAL STRENGTHS

\begin{tabular}{|l|c|c|c|c|}
\hline \multicolumn{1}{|c|}{ Masonry } & $\begin{array}{c}28 \text { day crushing } \\
\text { strength } \\
\text { MPA }\end{array}$ & Reinforcement & $\begin{array}{c}\text { Yield } \\
\left(f_{y}\right) \\
\text { MPá }\end{array}$ & $\begin{array}{c}\text { Ultimate } \\
\left(f_{u}\right) \\
\text { MPa }\end{array}$ \\
\hline Concrete block & 27.2 & D10 & 322 & 463 \\
Grout & 24.3 & D12 & 323 & 455 \\
Mortar & 13.9 & D16 & 297 & 436 \\
Prism* & 19.1 & D20 & 277 & 424 \\
\hline
\end{tabular}

* Average of two grouted 5 course prisms 


\section{LIST OF FIGURES}

FIGURE 1: Comparison of Measured and Theoretical Prism Strengths Using Equation 110

FIGURE 2: Mortar-Bed Confining Plate Being Placed in Compression zone of Masonry Shear Wall

FIGURE 3: Ductility of Masonry Walls for Aspect Ratio $A=3$

FIGURE 4: Masonry Frame Under Seismic Loading

FIGURE 5: Reinforcement of a Masonry Beam Section

FIGURE 6: Elastic and Plastic Displacements in a Masonry Beam/Column Unit

FIGURE 7: Dimensions and Reinforcement for Masonry Beam Column Test Unit

FIGURE 8: Masonry Beam Column Unit Test Set Up

FIGURE 8: Lateral Load-Displacement Hysteresis Loops for Masonry Beam/Column Test Unit

FIGURE 9: Lateral Load-Displacement Hysteresis Loops for Masonry Beam/Column Test Unit

FIGURE 10: Condition of Test Unit at End of Test $(\mu=10)$

FIGURE 11: Beam Reinforcement Stresses Through Joint Region

FIGURE 12: Horizontal Forces on Joint at $\mathrm{P}_{\mathrm{u}}=126.4 \mathrm{kN}$ 


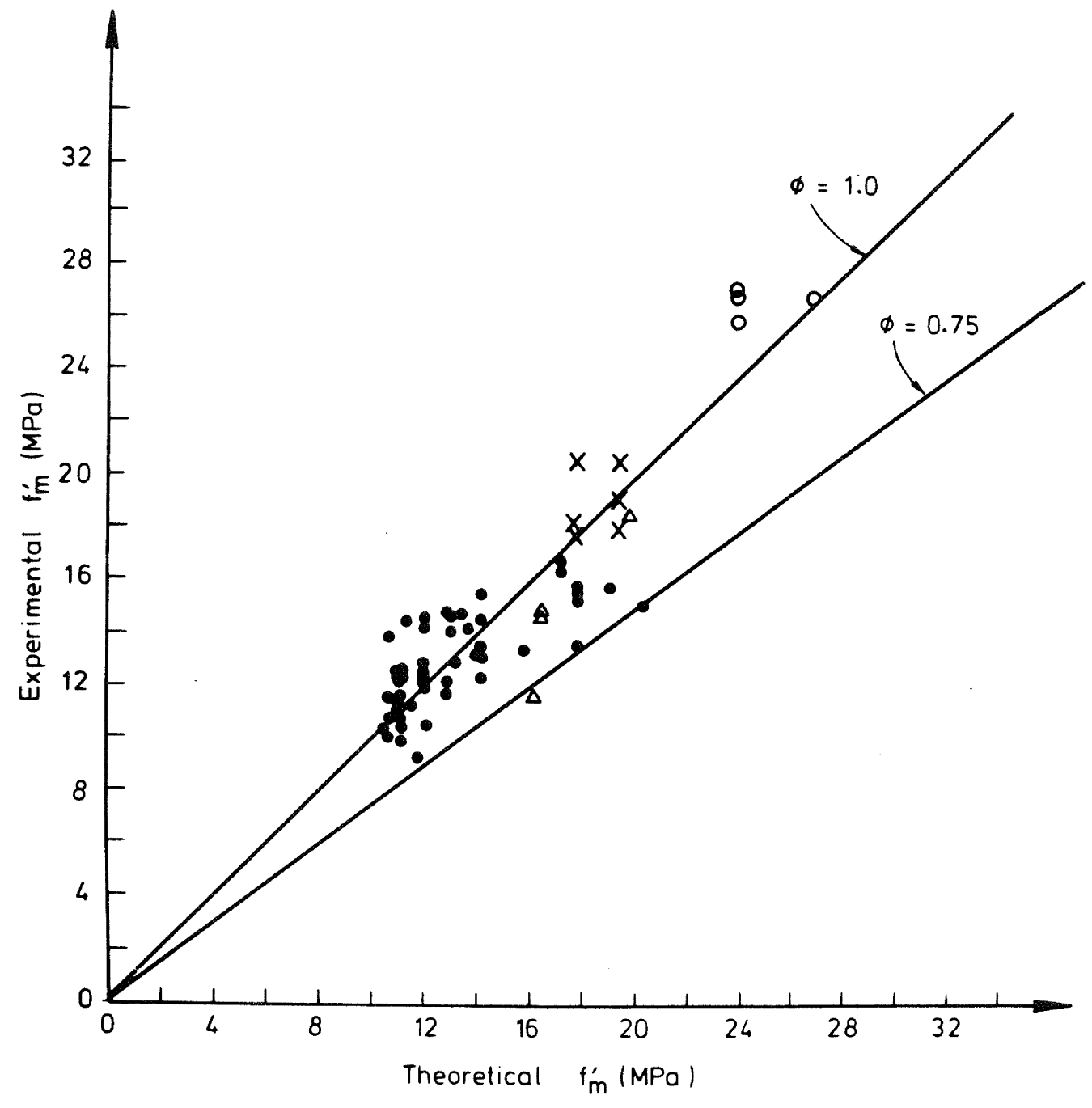

FIGURE 1 - COMPARISON OF MEASURED AND THEORETICAL PRISM STRENGTHS USING EQUATION 1 (10) 


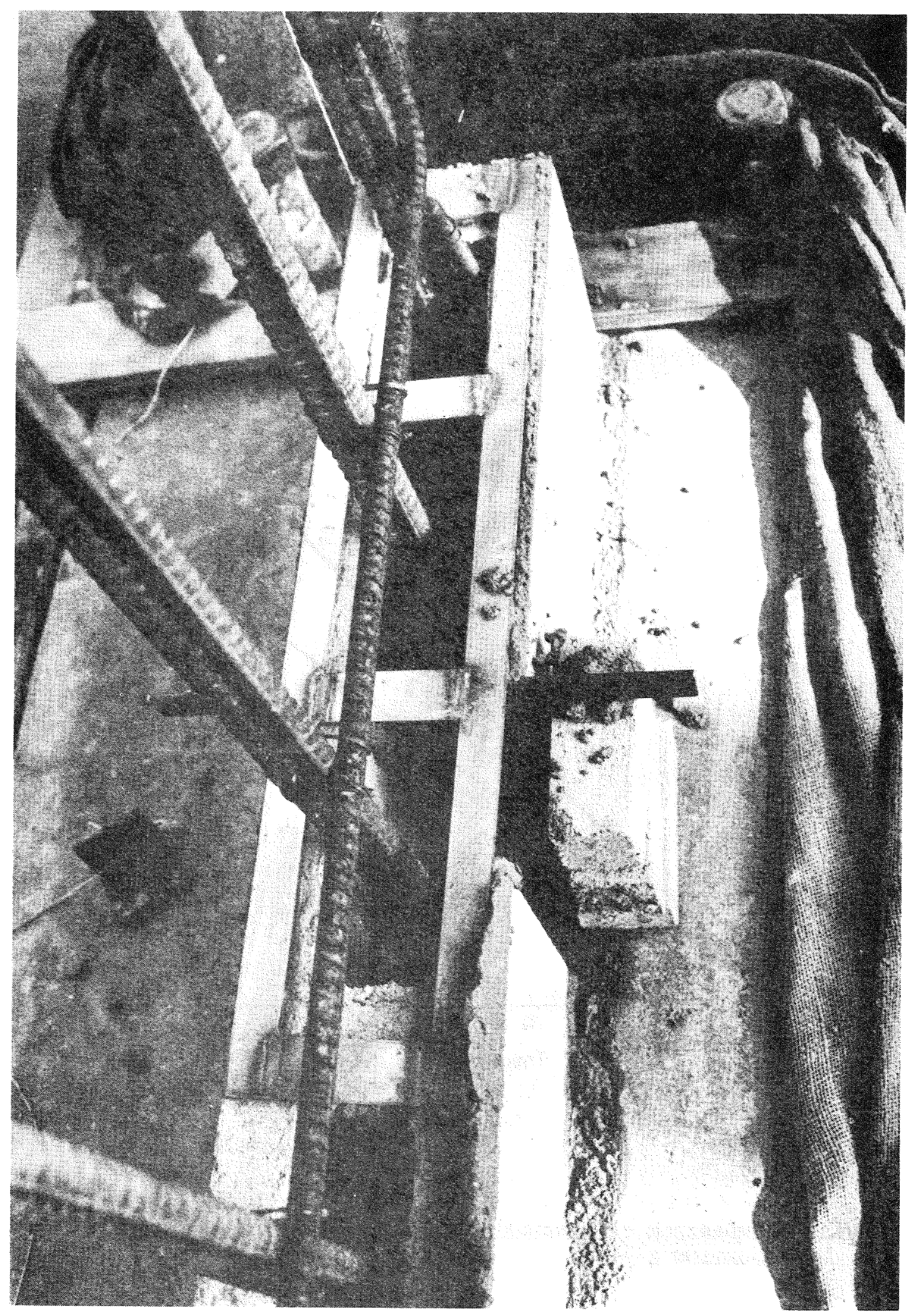




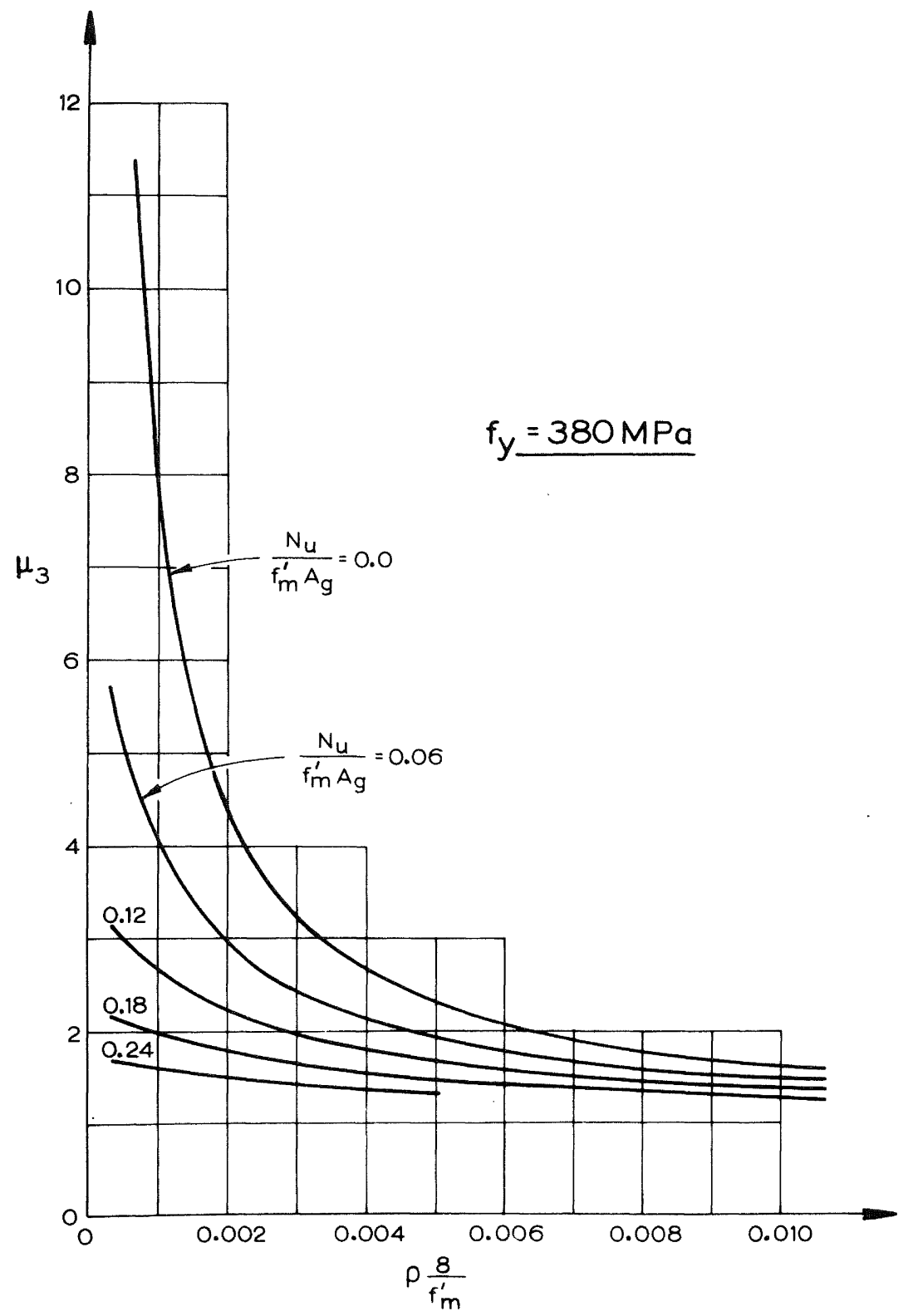

FIGURE 3 - DUCTILITY OF MASONRY WALLS FOR ASPECT RATIO A $=3$ 


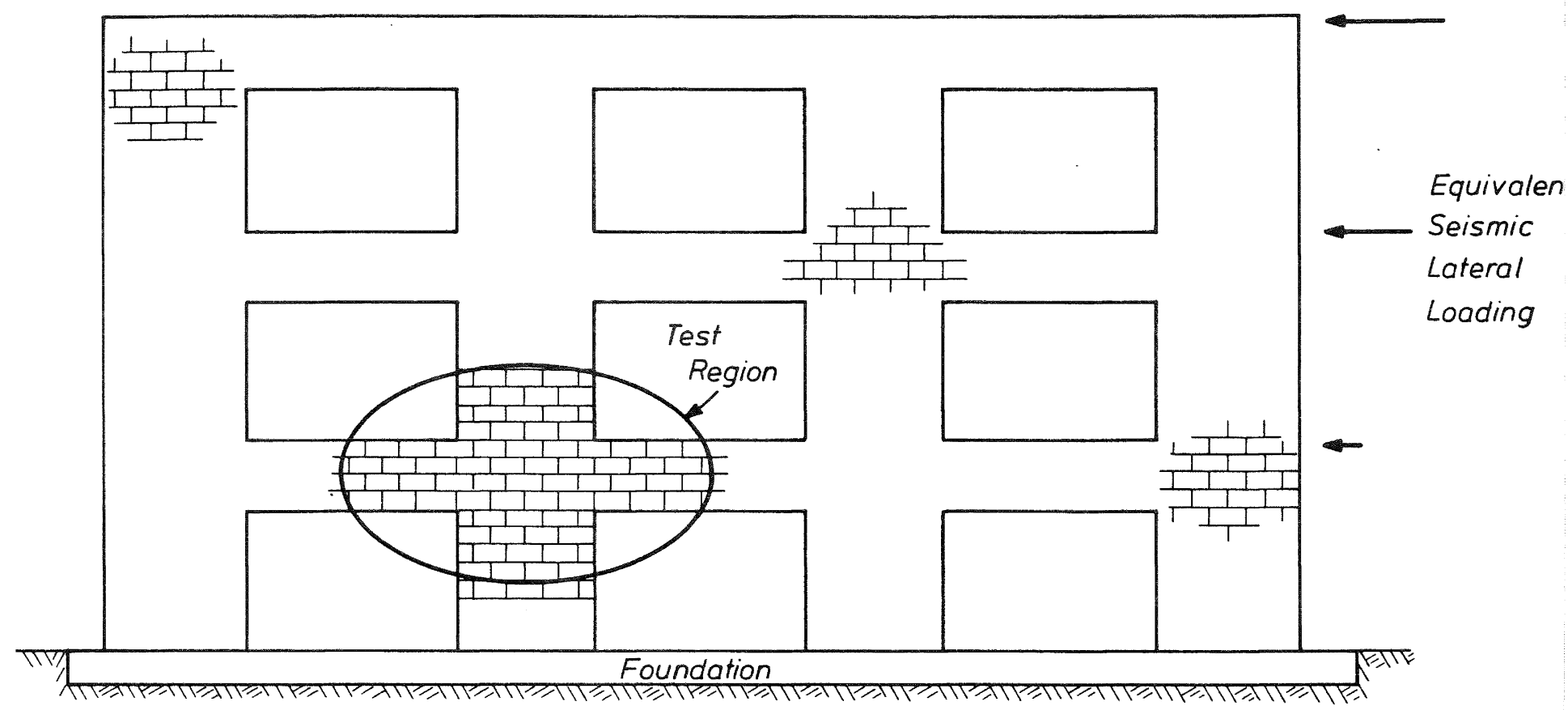

FIGURE 4 - MASONRY FRAME UNDER SEISMIC LOADING

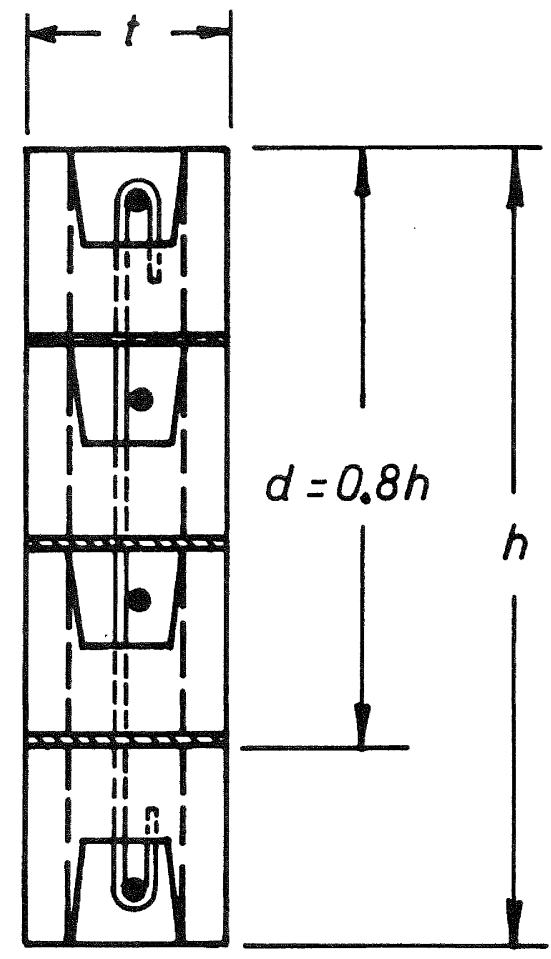




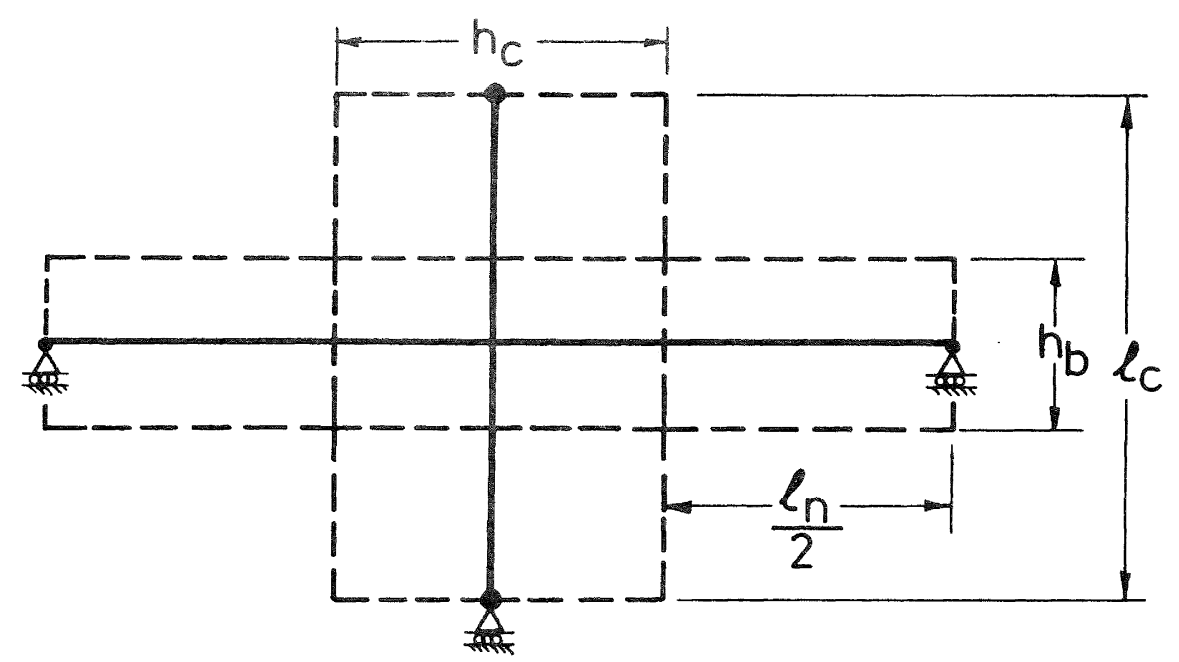

(a) DIMENSIONS

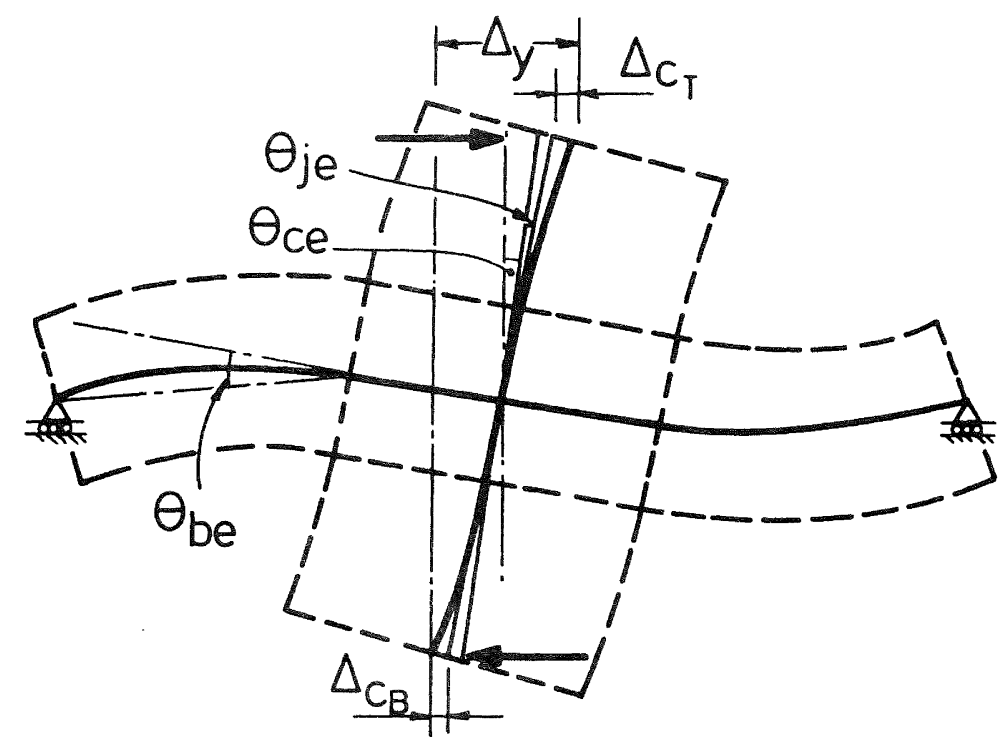

(b) ELASTIC COMPONENTS OF YIELD DISPLACEMENT

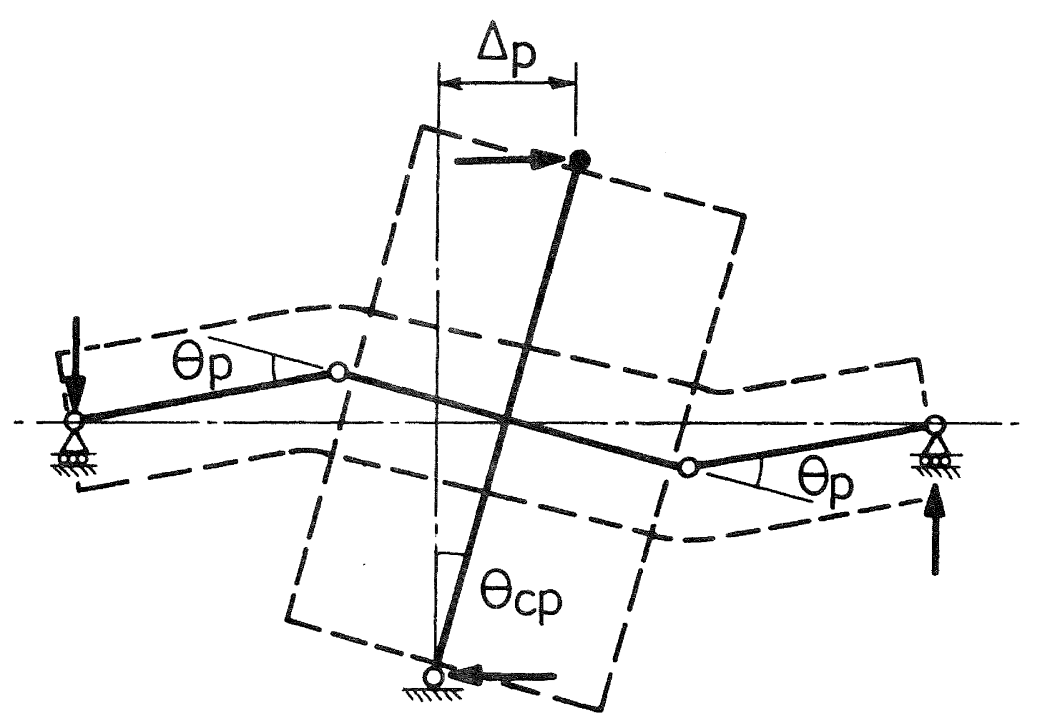

(c) PLASTIC DISPLACEMENT FROM BEAM HINGING 


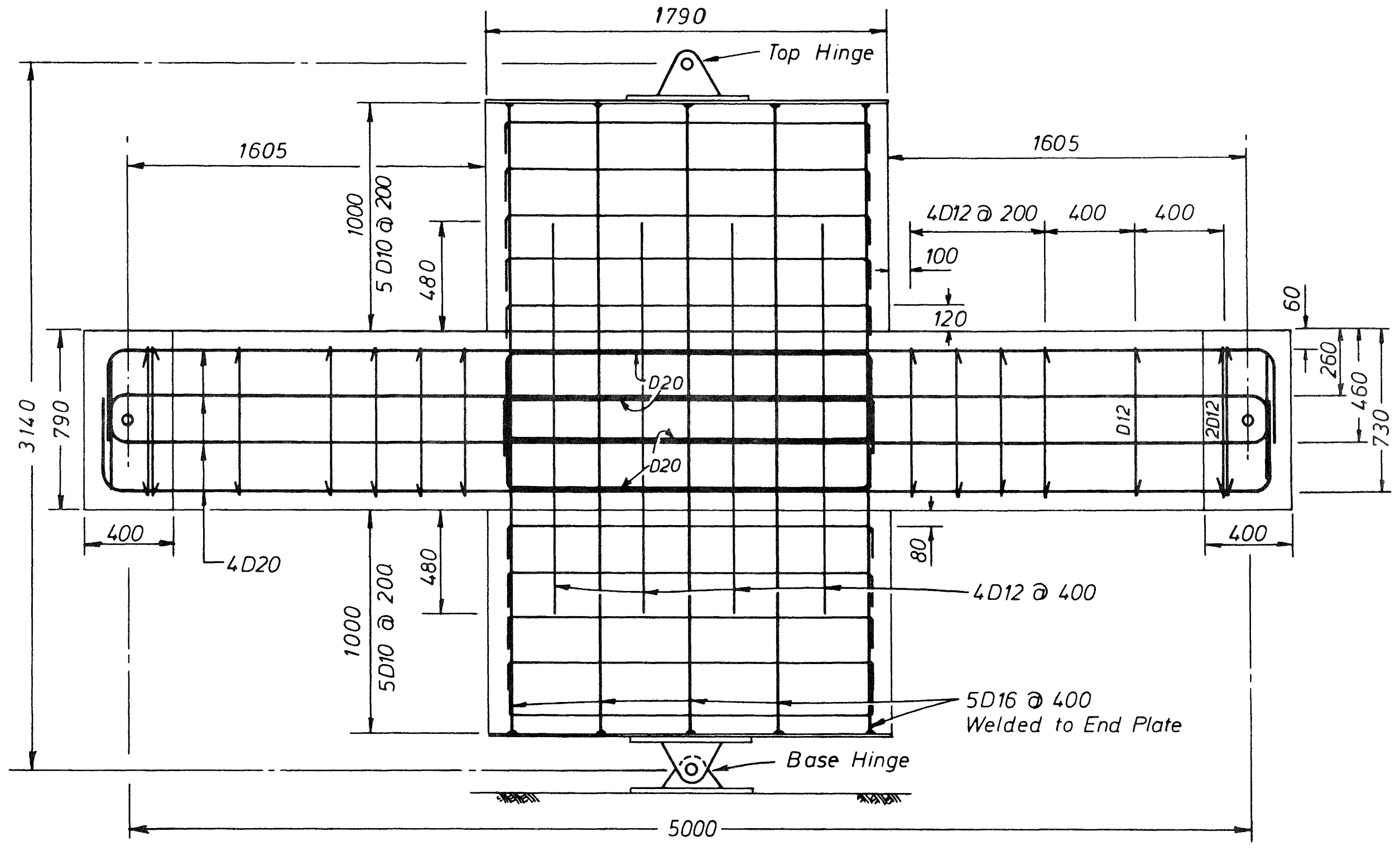

FIGURE 7 - DIMENSIONS AND REINFORCEMENT FOR MASONRY BEAM COLUMN TEST UNIT 


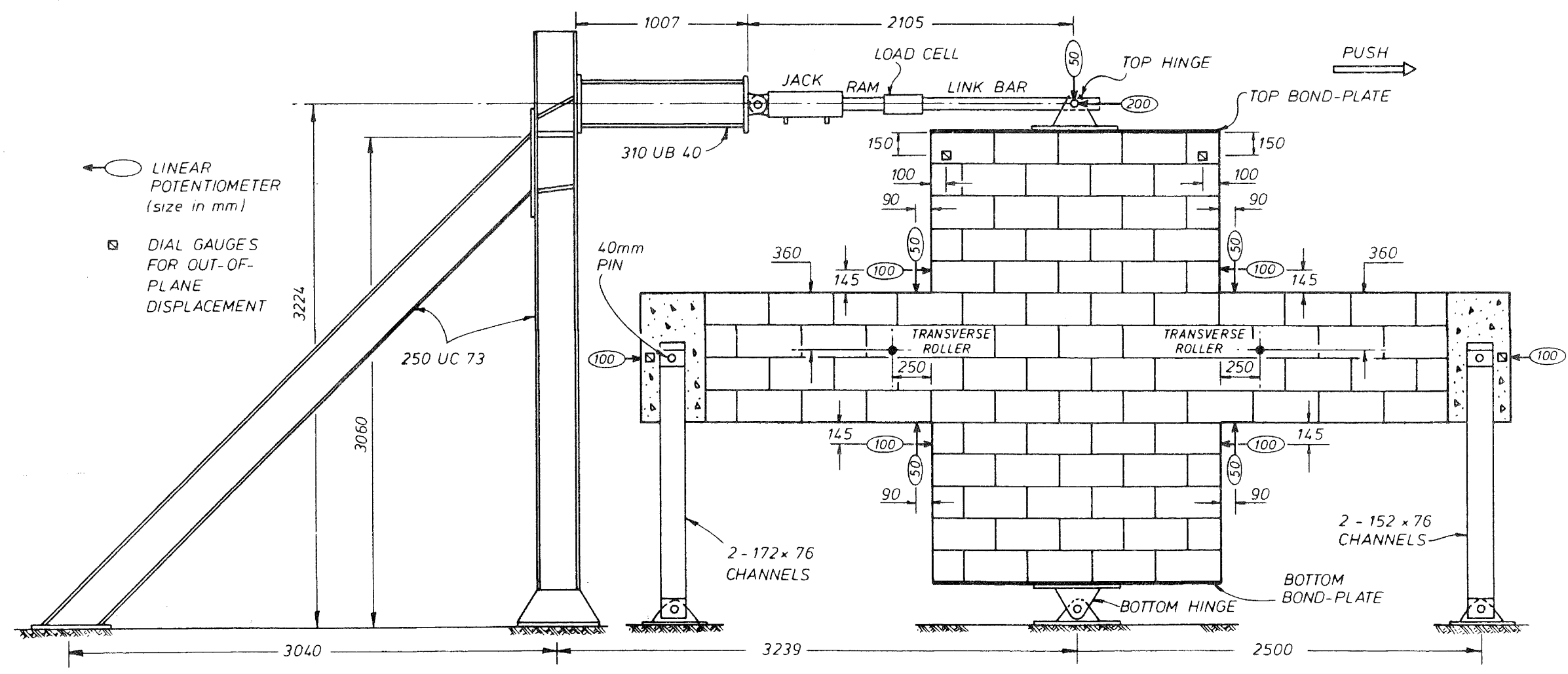

FIGURE 8 - MASONRY BEAM COLUMN UNIT TEST SET UP 


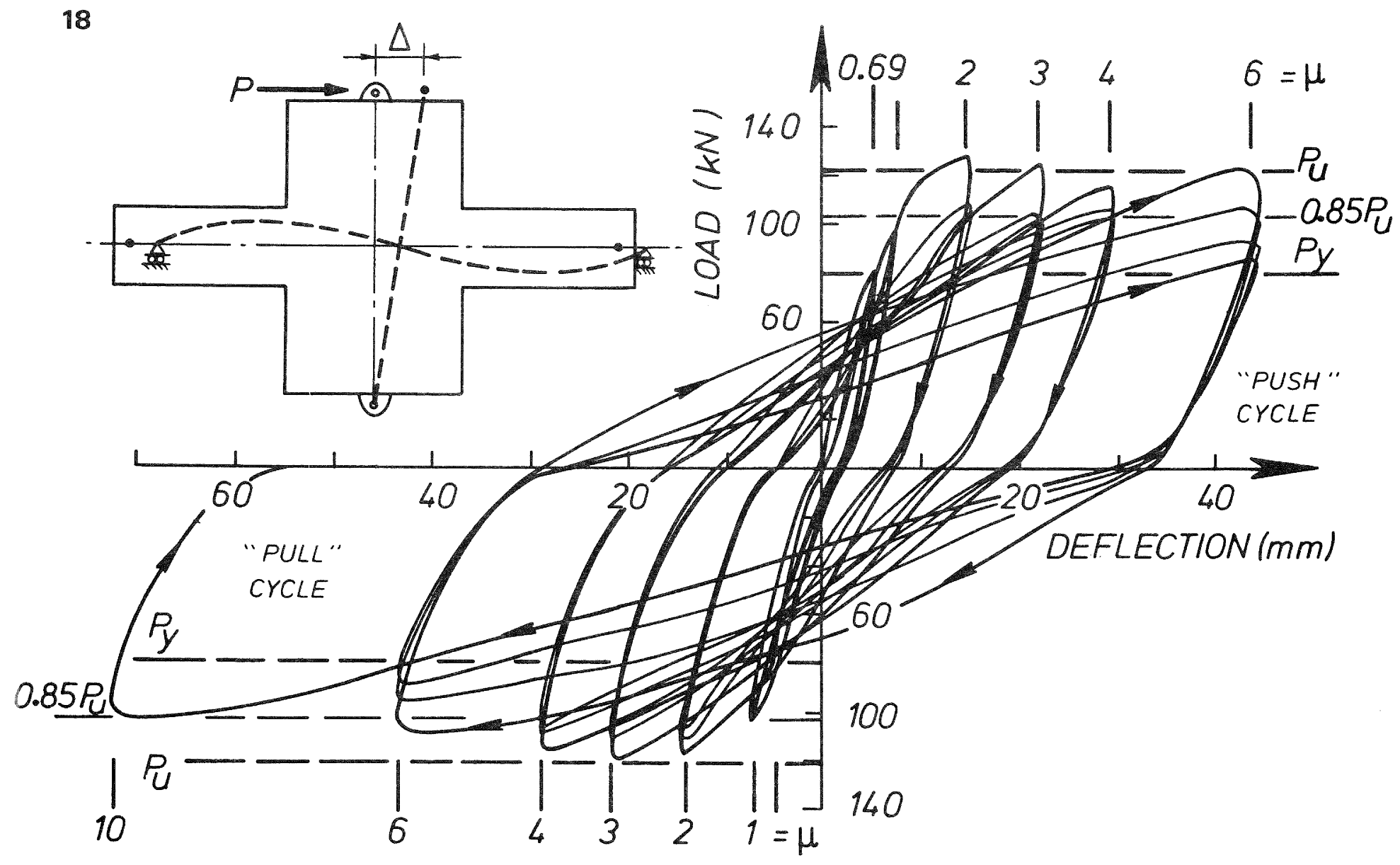

FIGURE 9 - LATERAL LOAD-DISPLACEMENT HYSTERESIS LOOPS FOR MASONRY BEAM-COLUMN TEST UNIT

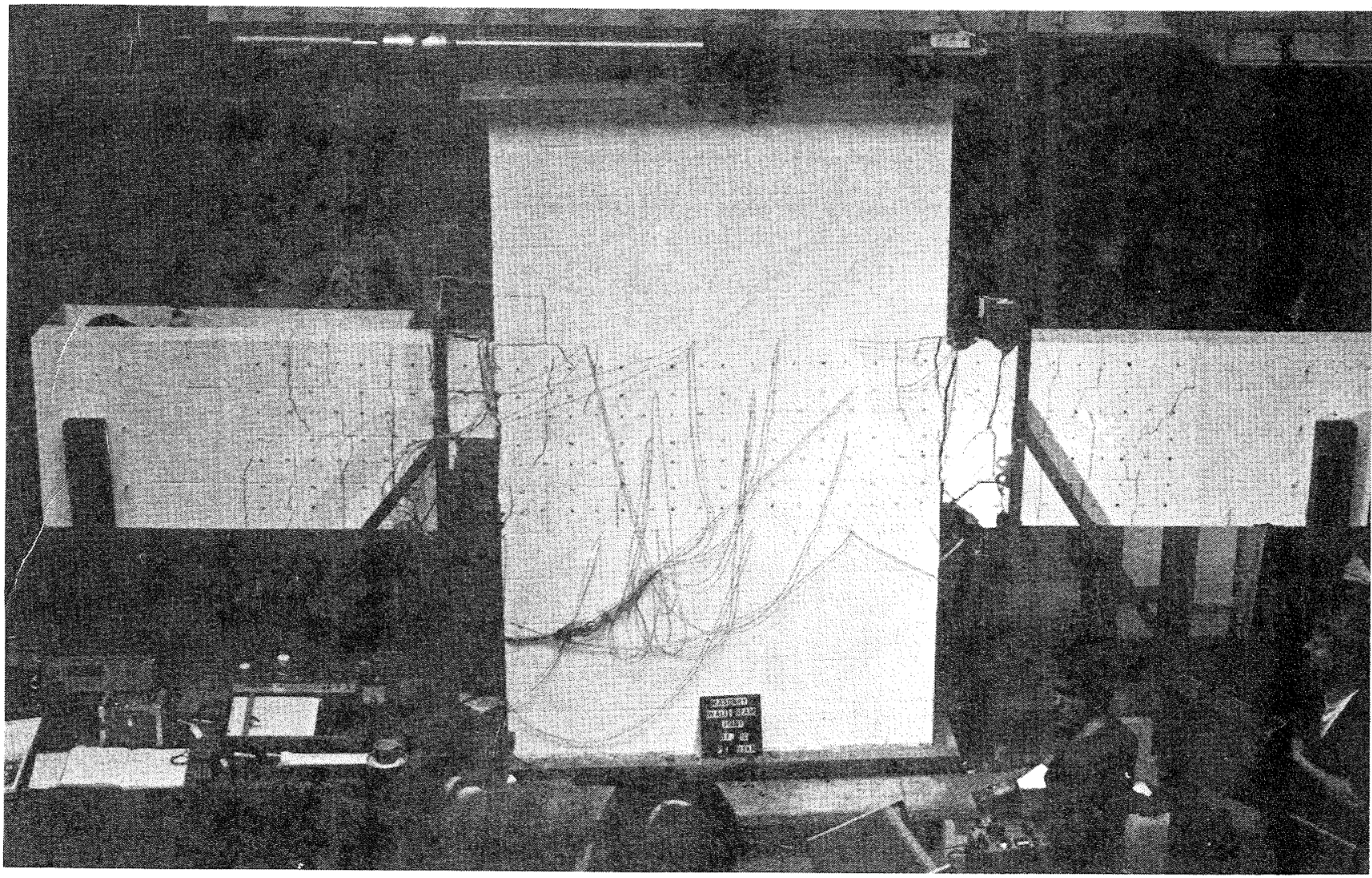

FIGURE 10 - CONDITION OF TEST UNIT AT END OF TEST $(\mu=10)$ 

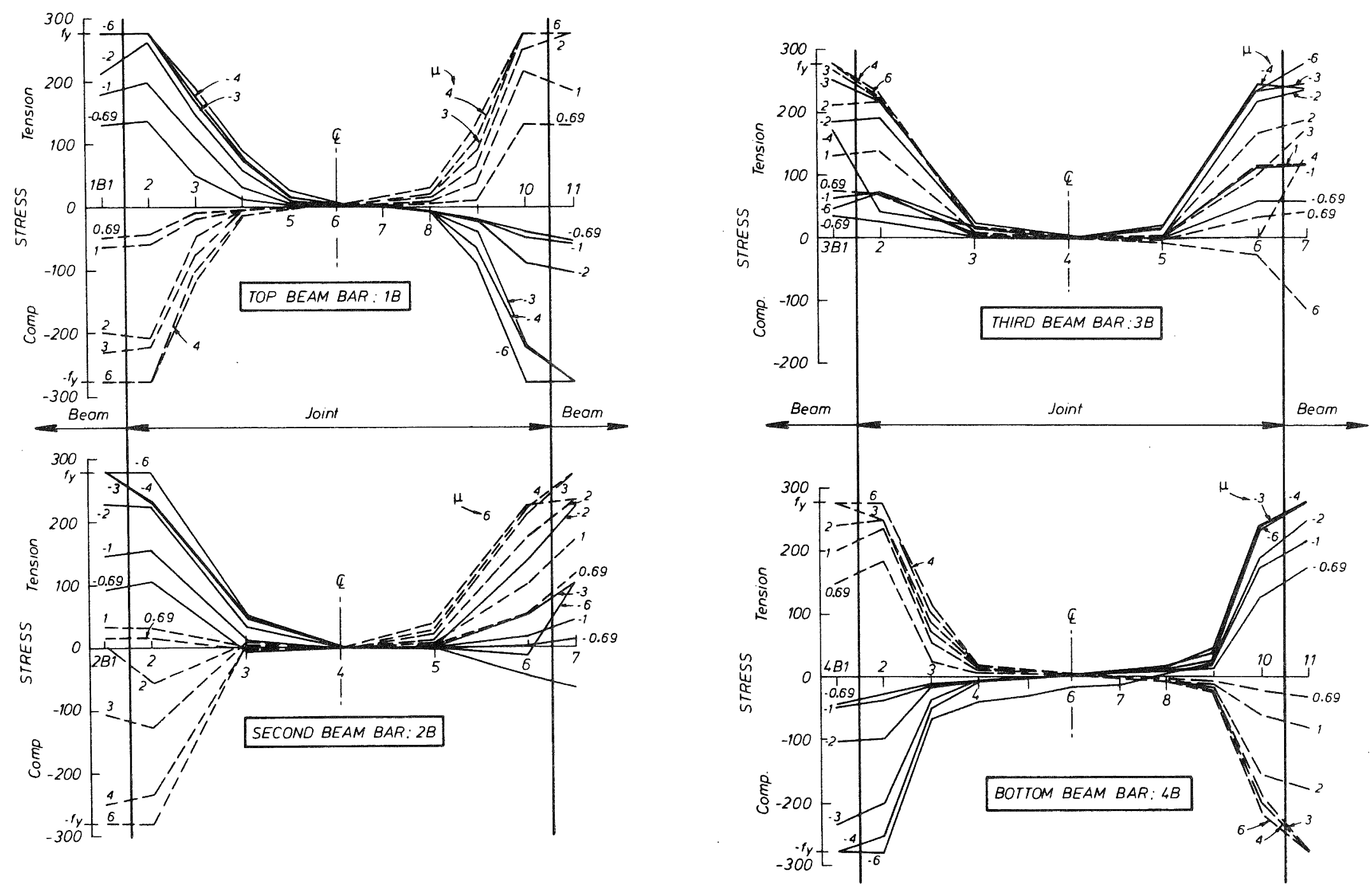

FIGURE 11 - BEAM REINFORCEMENT STRESSES THROUGH JOINT REGION 


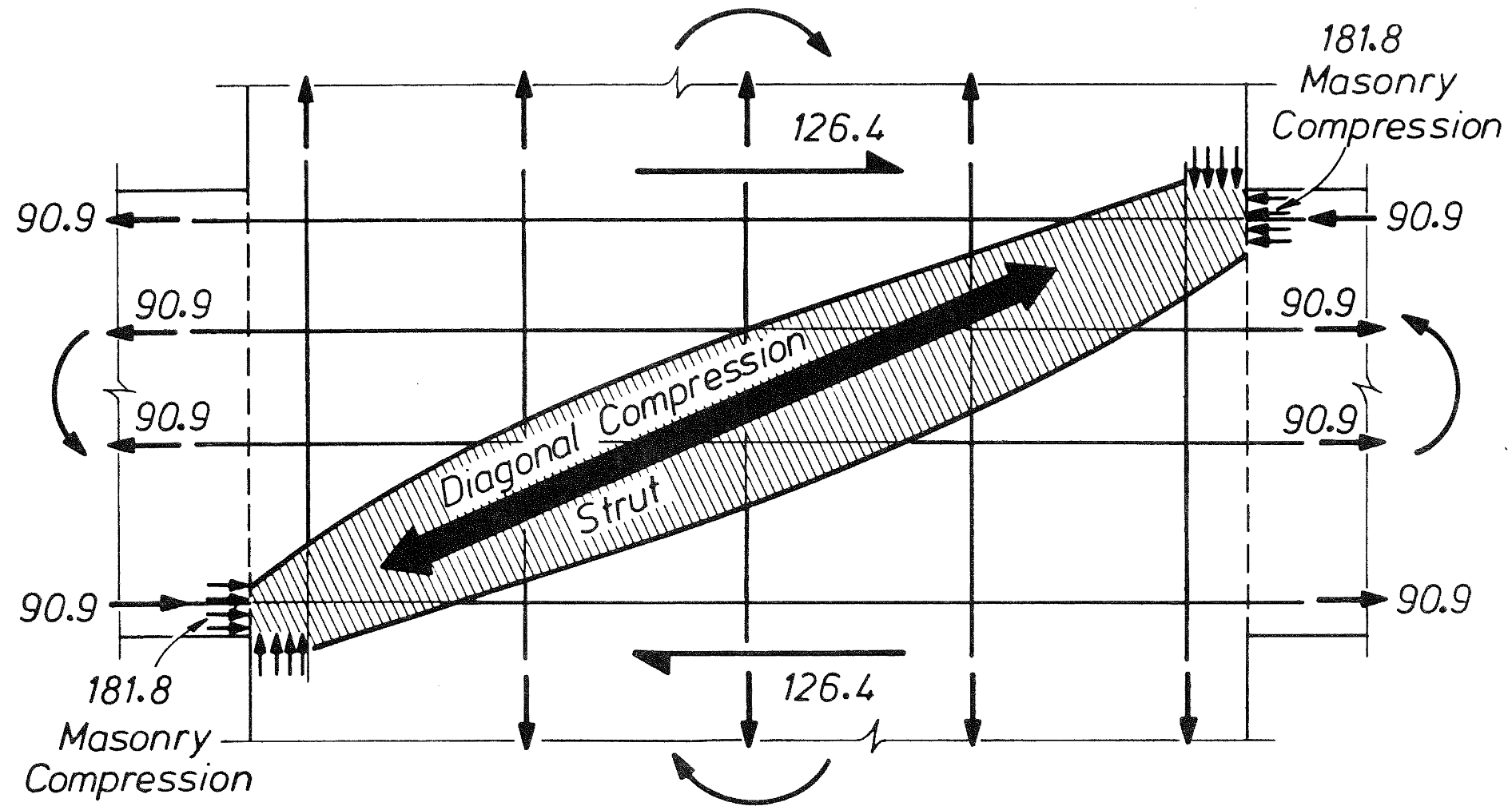

FIGURE 12 - HORIZONTAL FORCES ON JOINT AT $P_{u}=126.4 \mathrm{kN}$ 